\title{
Dillon, Grimes, McIntyre, and Pochan to Chair 2010 MRS Spring Meeting
}

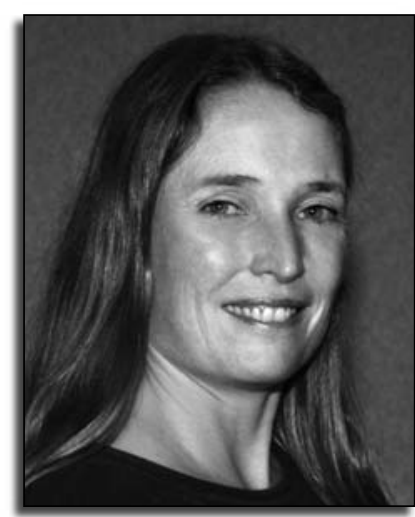

Anne C. Dillon

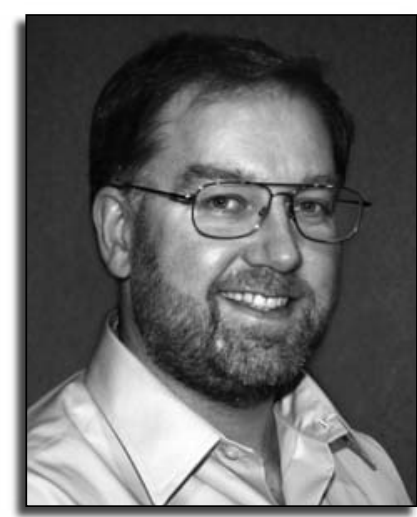

Robin W. Grimes

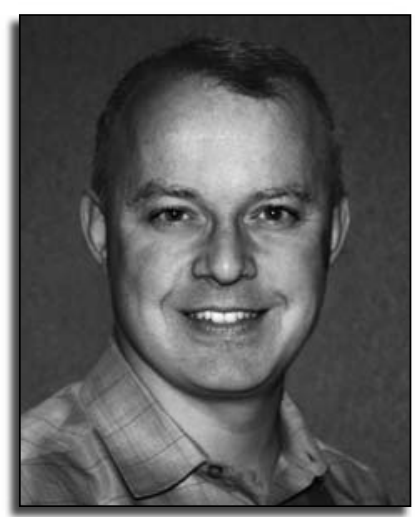

Paul C. McIntyre

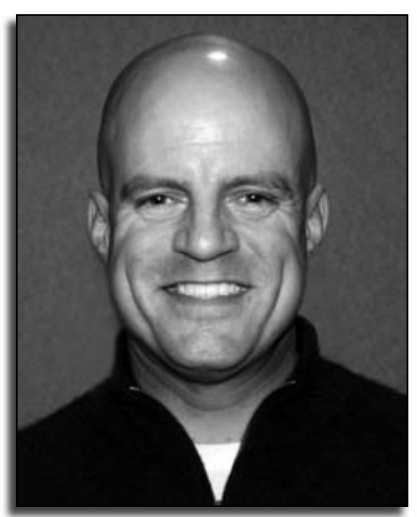

Darrin J. Pochan
Meeting Chairs for the 2010 Materials Research Society (MRS) Spring Meeting are Anne C. Dillon (National Renewable Energy Laboratory), Robin W. Grimes (Imperial College London), Paul C. McIntyre (Stanford University), and Darrin J. Pochan (University of Delaware). The meeting will be held in San Francisco on April 5-9.

Anne C. Dillon is currently a principal scientist at the National Renewable Energy Laboratory (NREL). Her research at NREL is focused on the synthesis and characterization of novel nanostructured materials, including single- and multiwalled carbon nanotubes as well as metal-oxide nanorods and particles. The nanostructures are targeted for a variety of renewable energy applications with an emphasis on electrical energy storage, electrochromic windows, and hydrogen sorption materials. She received BS degrees in both chemistry and history from the Massachusetts Institute of Technology in 1988 and a PhD degree in physical chemistry from Stanford University in 1993. Dillon came to NREL in 1994 as a postdoctoral researcher. She has over 80 peer-reviewed publications with approximately 4000 citations. She has been granted two patents. She received an NREL Staff Award in 2009.

Robin W. Grimes joined the Materials Department at Imperial College London in 1995 and was appointed the professor of Materials Physics in 2002, the same year he was awarded the Rosenhain Medal of the Institute of Materials. He spent the year 2000 at Los Alamos National Laboratory as the Bernd T. Matthias Scholar. Since 1984 he has authored over 180 peerreviewed publications and is presently on the editorial boards of the Journal of Materials Science and the Journal of Nuclear Materials. His primary research interest is the application and development of computer simulation techniques to predict structural and dynamic properties of inorganic materials. Topics of particular interest include radiation damage, nuclear fuels and waste form behavior, ionic conductivity and defect processes for fuel cell materials, surface structural processes, and interfaces between glass and ceramic. He is the principal investigator of the U.K. Research Council's multi-university initiative, "Keeping the Nuclear Option Open" and director of the Imperial College Centre for Nuclear Engineering.

Paul C. McIntyre is associate professor of Materials Science and Engineering and director of the Geballe Laboratory for Advanced Materials at Stanford University. He is a co-director of the Initiative in Nanoscale Materials and Processes at Stanford, and a founding member of Stanford's Nonvolatile Memory Technology Research Initiative. He focuses his research on nanostructured inorganic materials for applications in electronics, energy technologies, and sensors. He is best known for his work on metaloxide/semiconductor interfaces, ultrathin high- $k$ dielectrics, complex metal-oxide thin films, and nanostructured Si-Ge single crystals. McIntyre is an author of over 120 archival journal articles and inventor of six U.S. patents. He has received two IBM Faculty Awards and a Charles Lee Powell Foundation Faculty Scholarship in recognition of his group's research. He earned the BASc degree from the Materials Engineering Department at the University of British Columbia, Canada and the SCD degree from the Materials Science and Engineering Department at the Massachusetts Institute of Technology.

Darrin J. Pochan is currently professor in the Materials Science and Engineering Department as well as the Delaware Biotechnology Institute at the University of Delaware. Since joining the department in 1999 after receiving a PhD degree in Polymer Science and Engineering at the University of Massachusetts-Amherst and a National Research Council Postdoctoral fellowship at the National Institute of Standards and Technology in Gaithersburg, MD, he has developed a research program around the construction of new materials and nanostructures through molecular self-assembly mechanisms, biomaterials, and materials for nanotechnology and energy applications through organic/inorganic hybrids. Pochan's recent honors include an NSF Career Award, the DuPont Young Faculty Award, and the Dillon medal from the American Physical Society. Currently, Pochan also serves as associate editor for North America of Soft Matter, a new interdisciplinary journal from the Royal Society of Chemistry in the United Kingdom. 


\section{Anne Wagner (d. 2009)—A Personal Remembrance}

Anne Wagner, retired Administrative Assistant to the Materials Research Society's Executive Director, died on Saturday, May 9, after a lengthy battle with lung cancer.

Anne was the first employee I hired to staff the new MRS headquarters in Pittsburgh in late 1983. She told me several years later that she knew at the time of our interview that she would be joining the staff of MRS - she just wasn't sure how long it would take me to figure that out! Her title was simply Secretary to the Executive Director, which fails almost entirely to capture her role either in the fledgling headquarters or when it had grown to more than 40 staff members.

In the late 1980s and early 1990s, the rapid growth of the Society placed huge strains on everything we did, both on the side of the volunteers and staff. Because the headquarters was new, everything we did had to be developed from scratch, and Anne played a key role in facing those challenges, both by getting done the work that had to be done and in developing new processes to respond to the challenges, sometimes anticipating the challenges and being ready to meet them without having to be told what to do. MRS has always attracted creative and daring volunteers who, to use a phrase currently much in vogue, always "pushed the envelope." And push it, they did, mightily. Put all those elements together and you have an exceptionally challenging environment.

Anne thrived on the challenges. It goes without saying that intelligence and skill are required in such an environment. She was a key point of support for Society leaders-to Presidents, Meeting Chairs, Symposium Organizers, and Committee Chairs, and others. Always willing to help, to provide guidance, to do whatever was required.

But much more important than her competence were her personal qualities. Anne's abundant common sense was exceeded only by her tact and genuine caring for other people. She was always

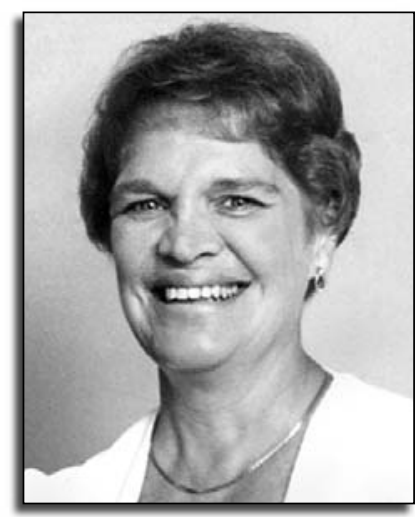

Anne Wagner

pleasant and upbeat. She was the one everyone on the staff went to when they were troubled, and she always helped them, unpretentiously and without fanfare.

She worked hard, but cheerfully, always displaying good humor and enjoying a good laugh. She was never concerned with formal authority or power, because her exceptional moral force gave her all the authority or power she ever needed. She was aware of the power she held through such a presence, but she was always truly modest and self-effacing in exercising it. Perhaps the best way to summarize Anne's style was that she matched the creativity and drive of MRS volunteers with comparable drive and dedication to assure that MRS headquarters delivered what was needed to ensure the success of the vision of Society leaders.

Anne's devotion to MRS was extraordinary. She repeatedly put the needs of the Society before her own convenience. The best example of this was that shortly before the MRS Fall Meeting in the mid1990s, she learned that she had breast cancer. She intended to schedule treatment as soon as she returned from the meeting, but at my insistence that she seek immediate treatment, for the only time of which I am aware, she put herself first. Her treatment was successful and she celebrated many years of health.
When Anne retired in 1997, the staff created the "Annie Award" in her honor. Given annually, the award recognizes the staff member whose attributes emulate hers-a high level of performance in professional responsibilities but also substantial contributions to the well-being of the MRS staff. Anne returned every year to present the award. Without any hint of unseemly pride, Anne was fully aware of her professional competence and the extent to which she exemplified extraordinary caring for staff members, and she took great pleasure in seeing another staff member honored each year for displaying similar characteristics; however, it is fair to say that she was emulated but never equaled.

Anne was devoted to her daughter and two sons and to her three granddaughters, in whose accomplishments she took great pleasure. At her funeral mass, the eulogy was presented by her son Don Glaser, who eloquently captured her essence with accuracy, brevity, and warmth. Anne would have been proud of him.

Anne faced many difficulties in her life, but she faced them all with a grace, courage, and serenity that would be difficult to exaggerate. She thought of herself as an ordinary person, but she was one of the people I most admired. She contributed much to the benefit of MRS members, most of which most members have no idea. It wasn't important to her that they know, only that future generations of members continue to benefit from the work of a substantial part of her life. Anne set the standards for the core characteristics of MRS employees during the formative years of the Society's headquarters; those core characteristics remain embedded in the culture of MRS headquarters, and will remain as her legacy so long as MRS staff members follow her professional commitment to their jobs and caring for MRS members and colleagues.

JOHN BALLANCE

Former MRS Executive Director (1983-2008)

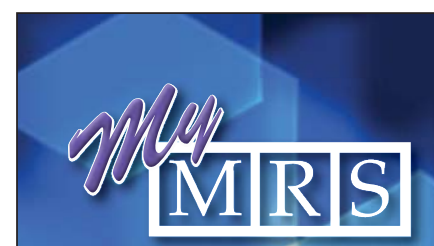

whw.mrs.org/mymrs

This feature of the MRS Web site allows you to personalize the information you receive from usidentify your particular areas of interest, register for/manage your online newsletters and alerts, change your password, and update your contact information.

MATERIALS RESEARCH SOCIETY - Advancing materials. Improving the quality of life. 